\title{
CORPO E LINGUAGEM
}

RAFAEL VOGT MAIA ROSA entrevista a performer e coreógrafa norte-americana K.J. Holmes

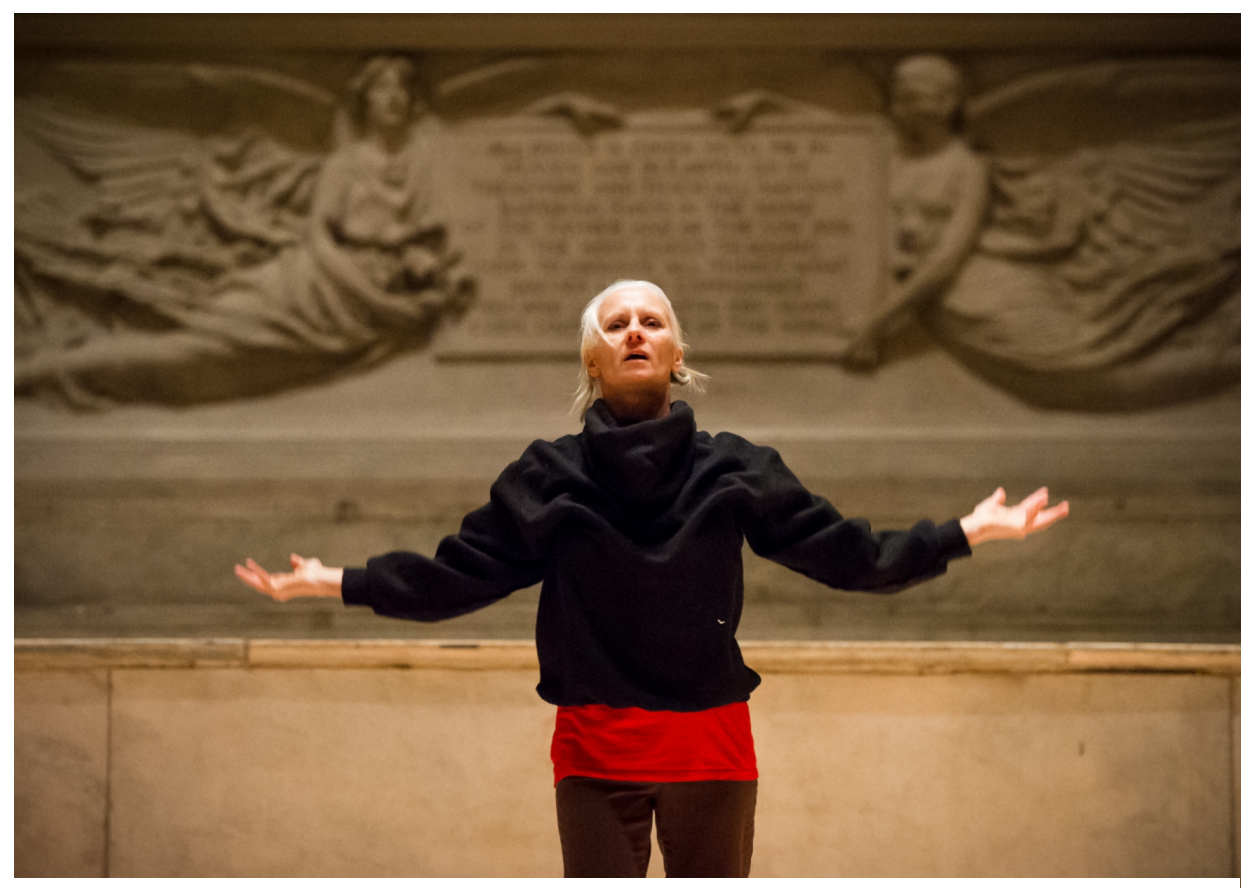

foto: Ian Douglas

Na discussão sobre o contemporâneo nas artes, a performance e a dança são modalidades que exacerbam a problemática da não-autonomia da obra de arte e de sua relação com o público. Essa questão já está possivelmente mais desgastada nos EUA e na Europa, mas mobiliza ainda a desconfiança de segmentos da crítica no Brasil, por exemplo, onde, apesar de esforços isolados, a tradição nesse campo é incipiente.

O trabalho de K.J. Holmes esteve, desde o início dos anos 80, particularmente associado ao "contato improvisação". Essa modalidade, como a maior parte das práticas performáticas que passaram a ser 
experimentadas já no final da década de 1940, reduz drasticamente os elementos narrativos associados à coreografia. Como o próprio nome já diz, o improviso predomina sobre qualquer nível de representação. Hoje, ela é professora da NYU no curso de teatro experimental e artista residente no Movement Research, núcleo associado aos primórdios da dança contemporânea nos EUA. Na última década, curiosamente, ela fez incursões a métodos tradicionais de atuação e retomou estudos de canto, o que modificou sensivelmente sua poética.

Esta entrevista foi motivada particularmente pela apresentação de trecho do work in progress "HIC SVNT DRACONES", em ciclo promovido na Judson Memorial Church, em Nova York. Nele, Holmes consegue uma indistinção do que é improviso e do que é representação. Com esse suporte, ela introduz, então, uma personagem que incorpora um tipo de realismo no qual se conjugam falas prosaicas, expressões vocais e um gestual depurado numa narrativa absorvente embora parcialmente irreconhecível.

\section{Você poderia falar sobre seu percurso?}

K.J. HOLMES - Eu comecei praticando balé clássico, quando criança, parei e me tornei uma espécie de cantora até minha adolescência, cantava em corais e igrejas. Ainda na adolescência, voltei a dançar, retomei o balé e me iniciei na dança moderna, no jazz. Cresci em Nova Jersey, em uma cidade pequena, subúrbio de Nova York, e gostava muito dos musicais. A ideia de dançar, atuar e cantar era algo a que eu estava bastante exposta pela proximidade com Manhattan, onde costumávamos ir a shows sempre. Depois de terminar a escola, me senti atraída por algo em torno da terapia associada à dança. Frequentei uma faculdade de dança-terapia, por um tempo, no Colorado, e compreendi que eu realmente queria ser uma performer. Nunca pensei em me mudar para Nova York, mas depois dessa experiência, numa cidade mais distante, percebi que era preciso. Uma vez aqui, então, passei a ter contato com o trabalho de Andre Bernard, que ensinava ideokinesis, que é o uso de imagens para se entrar em contato com um "apoio profundo" ["deep suport"] para movimentação, e isso me levou a descobrir a improvisação e diferentes tipos de "estudos somáticos" ["somatic work"]. Logo, minha dança esteve sempre muito influenciada pelo BMC body-mind centering, 
contato e improvisação, e pelo trabalho de Lisa Nelson com tuning scores, basicamente o uso de sua percepção corporal para compor.

\section{Movimentos.}

K.J. HOLMES - Movimentos. Ela [Nelson] trabalhava com a ideia de percepção como ferramenta para se criarem "partituras" de movimentos por meio da medição de uma explosão, antes que isso se transformasse em outra coisa.

\section{É um vocabulário próximo da música.}

K.J. HOLMES - Definitivamente. Em muitos dos “estudos somáticos”, especialmente o body-mind centering, uma das questões que se investiga são os diferentes ritmos fisiológicos, a partir do acesso a diferentes sistemas do corpo como o esqueleto, órgãos, circulação. E cada sistema tem sua vibração própria, diferentes qualidades de ressonância, o que é música; como se acessassem diferentes instrumentos, algo que tocamos, diferentes sons, diferentes tonalidades, diferentes qualidades de narração baseadas no sistema corporal. A partir de 2007, eu me interessei por teatro. Estive envolvida com Meisner Training no Esper Studio e também com Fay Simpson e seu trabalho com o "corpo lúcido" ["lucid body"], sistemas de energia que incorporam personagens. Hoje acredito que meu trabalho é, paralelamente ao canto, uma tentativa de criar uma ponte entre o movimento e o teatro através de diferentes sistemas.

\section{Você inclui nisso o teatro realista?}

K.J. HOLMES- Sim, com atuação em algumas peças e em um filme que será laçado no ano que vem.

\section{Acredita que o realismo, no sentido de se criar uma narrativa com personagens verossímeis, seja uma espécie de via paralela e contínua na cultura norte-americana? \\ K.J. HOLMES - Eu não sei... O fato é que me sinto um pouco perplexa no lugar em que me coloco quando trabalho como atriz. Quando vou assistir a teatro tradicional, não penso que seja aquilo. E, quando vejo peças totalmente experimentais, também não. Mas realmente aprecio a sabedoria de alguns dramaturgos com vocação realista, sua habilidade de, com a dramaturgia realista, captar uma determinada condição}


humana. Quando me envolvi com o método Meisner, basicamente sentia falta de algo em meu trabalho com dança, como ter uma qualidade emocional ou um sentido de "história". Não que eu quisesse abordar um tema específico, mas parecia faltar algo de humano no interior do corpo. Porque tudo era muito voltado às sutilezas, abstração, o momentum, o físico... Muito do que eu fazia era bastante atlético, tinha a ver com colisão. Mas persistia uma questão sobre "o que mais eu quero dizer", especialmente quanto ao que está acontecendo no mundo, a que eu queria me referir.

Você sente alguma resistência ao "experimental” nos EUA? Por exemplo, o dramaturgo David Mamet considera "experiências de vanguarda", obras em que você não se absorve pela "história", algo "ditatorial".

K.J. HOLMES - Eu me sinto inclinada a dar voz apenas a uma história que um dramaturgo como Tennessee Williams ou Eugene O’Neill escreveria. Quer dizer, cavar fundo nessa dimensão da personagem. Mas isso não exclui a natureza experimental no uso de material para o trabalho. Digo, a peça que apresentei na Judson Church emprestava palavras de procedência diversa, mas era quase totalmente coreografada, escrita previamente. Havia um ou outro momento de improvisação, mas era bastante estruturado, eu sabia toda a sequência.

\section{Portanto com um sentido claro de representação.}

K.J. HOLMES - Sim. A improvisação fica por conta da presença do público e como trabalhar com ela, como trabalhar com esse fator. E talvez essa seja essa linha que separa o teatro realista do experimental, onde há uma relação direta com a plateia e o afeto, o desejo de mobilizá-la direta e indiretamente pela linguagem. Isso acontece com o movimento também, mas eu estou interessada no poder das palavras e nesse limite.

\section{Você tem interesse pelo processo de filmagem?}

K.J. HOLMES - Tenho curiosidade em relação aos filmes, mas penso mais em usá-los em performances ao vivo, em minhas performances, quero dizer. Agora, paralelamente, estou envolvida como atriz em um filme, e é bom ser dirigida, depois de ter trabalhado tanto com minha própria produção. Gosto de me colocar na mão de alguém que me diga o que 
fazer, de uma certa forma, para que possa explorar outras de minhas possibilidades que eu não poderia trazer em meu próprio trabalho.

Em um filme feito durante um trabalho colaborativo seu, em Bearnstow, Maine, você diz que "não saberia dizer o que estamos fazendo exatamente, mas não está mais ligado aos ideais pósmodernos". Isso aponta para quê? Chamaria de contemporâneo? K.J. HOLMES - Acredito que o que eu faço não possa ser incluído na ideia de pós-moderno porque grande parte de meus mentores vieram dessa “época” em que se pensava em trazer o corpo para uma dimensão mais pedestre e vê-lo como algo dissociado da emoção, da representação. E para mim, no trabalho contemporâneo, mesmo não havendo uma única maneira de defini-lo, existe uma relação entre o corpo e a linguagem. E acredito que isso vem acontecendo cada vez mais. Digo, o texto sempre foi usado, mas venho colaborando em projetos como o de Miguel Gutierrez \& The Powerful People, e este é um ótimo exemplo de trabalho contemporâneo por ser capaz de pegar algo bastante pessoal e desdobrar isso em algo abrangente. Eles estão misturando linguagens, canção, movimento e são bastante rigorosos em relação a cada um desses aspectos. Ou seja, não é um musical, mas é algo que está empregando elementos diversos da atuação. Depois de vir treinando o corpo para que ele seja um instrumento eficiente, a gente se pergunta: onde está o humano dentro disso, quais são os limites, onde está o conflito? É isso o que eu sinto que tem nessa nova peça.

A sua personagem, nesse caso, parece prosaica, mas surpreendentemente reativa a um ambiente externo. É como se ela conseguisse comunicar com clareza uma certa paranoia.

K.J. HOLMES - Estou explorando as barreiras entre sanidade e insanidade e o que define isso. Ou seja, não se trata de criar uma personagem "louca", mas de se perguntar sobre qual é o extremo, até onde alguém pode ir nesse sentido em termos de expressão, sem que se "rotule" a personagem como um "indigente" ou algo "fora do mundo".

A Judson Church, onde você realizou essa performance, é uma igreja no centro de uma metrópole. Você acha que o que se apresenta lá reivindica uma espécie de "dessacralização", desinstitucionaliza o lugar 
e o devolve para um uso comum?

K.J. HOLMES - A Judson é um lugar histórico, que se tornou um abrigo para ativistas nos anos 60 e que também acolheu os dançarinos do Grand Union que de fato faziam performances. Outras igrejas fazem isso. Fui recentemente a um espetáculo que chegava a ser pornográfico. Eu me perguntei o que um clérigo pensaria sobre aquilo. Mas eu penso que o edifício de uma igreja é arquitetonicamente receptivo a essas manifestações. A Judson definitivamente.

Trisha Brown tem esse trabalho do início dos anos $70 \mathrm{em}$ que ela e outros dançarinos se apresentam em coberturas e telhados, explorando uma camada que parece se contrapor à verticalidade da cidade de Nova York. Você acha que esse é um lugar que gera uma reação corporal mais específica em relação à configuração urbana? K.J. HOLMES - Acredito que exista algo relacionado à geometria que cria um determinado tipo de rigor. Eu trabalhei em São Francisco por um tempo, que é um lugar de que gosto muito, mas senti como se não tivesse a concentração que tenho quando estou aqui, uma massa crítica, um estímulo, o murmúrio vital. Talvez haja mesmo um magnetismo envolvido.

Li que você está envolvida com ioga. Essa prática era alternativa, contracultural até, na época de John Cage e Merce Cunningham, e hoje está completamente disseminada. Como essa cultura entra em seu trabalho e em que medida ela pode modificar a predisposição do público em relação às artes do corpo?

K.J. HOLMES - Eu pratiquei ioga na adolescência e lembro que a primeira aula que tive foi uma experiência profunda. E imaginei que voltaria a praticar quando fosse mais velha. Foi como se eu entendesse algo a respeito de uma estabilidade que eu nem sabia estar me faltando. Algo sobre ser mais ancorado - e eu tendo a ir a mais de uma direção ao mesmo tempo. Mais tarde, comecei a trabalhar com contato e improvisação, que tem muito a ver com se reformular, desconstruir os movimentos básicos, rolar, se arrastar e retomar o lugar vertical que você mencionou que Trisha Brown estava desafiando. Um de meus primeiros professores desse tipo de movimentação usava a ioga como aquecimento. Eu penso que a prática mais aprofundada me levou a algo 
mais individual, nesse sentido. Porque o contato e a improvisação são uma prática coletiva. Agora, do ponto de vista cultural isso se tornou uma questão mercadológica, de consumo, neste país. Mas pode ser também uma resposta a um mundo tecnológico, o mundo do computador. Atualmente, tendo a separar a ioga da dança e ter isso como algo mais pessoal.

Em relação ainda a essa desconstrução que mencionou, você conheceu pessoas realmente capazes de uma movimentação livre de uma pressão externa por padrões?

K.J. HOLMES - Sim. Simone Forti. Ela trabalhou muito com estudos de movimentos primários dos animais... O próprio Steve Paxton no desenvolvimento do contato e improvisação. Posteriormente, algumas coisas que eram experiências podem se tornar técnicas, e as pessoas se inclinam à forma no lugar da pesquisa. Mesmo o body-mind centering é hoje algo mais codificado, ao passo que uma das razões originais dessa prática era ver o que você conseguia “encontrar". Ou seja, mesmo sabendo mais, como se poderia saber ainda mais permanecendo "sem saber".

\section{E a respiração?}

K.J. HOLMES - Bonnie Cohen, que foi quem desenvolveu o body-mind centering, fala em trazer a atenção para qualquer coisa, uma coisa sintomática que é algo que o corpo faria de todo modo, não intencionalmente; e, quando você atenta para isso, você pode começar a trabalhá-lo. Se nos focamos na respiração, que é algo que não vai parar e que acontece continuamente, podemos estende-la, podemos começar a usar a imaginação em relação a ela.

\section{E dar forma como elemento expressivo?}

K.J. HOLMES - Certamente. Ela permite desenvolver um senso de presença como performer. Porque, quando você chega à respiração, você pode brincar com qualquer padrão que tenha e trazer isso para a personagem.

Em sua peça você fez transições entre fala, canto e sons guturais. Como é essa operação?

K.J. HOLMES - Uma das coisas que venho explorando no trabalho, em um 
nível físico, é o sistema glandular do corpo, o sistema endócrino, ou seja, químico. E, para explorar essa instância, a vibração é bastante alta. $\mathrm{E}$ essa frequência de alta vibração é ao mesmo tempo a mais pessoal e a mais arquetípica em nós. Então naquela abertura vocal que eu utilizei eu estava trabalhando com a respiração em diferentes centros e permitindo sons e diferentes arquétipos. Eu talvez ainda não tenha dominado isso completamente, mas atravessei todos eles em uma espécie de aquecimento para o texto. Então, o primeiro som, que era bem grave, estava concentrado em algo como o primeiro chacra, que está conectado com o solo. É bem grave, e a vibração é a mais baixa. E ele de fato traz um sentido de "alguém" em mim.

\begin{abstract}
Algo estranho a você?
K.J. HOLMES - Estranho, mas também amplo. E, se eu mudo isso para uma outra parte, que é algo que Fay Simpson explorou com a ideia de "corpo lúcido", se eu mudo a atenção da respiração, da vibração, que tipo de percepção física pode vir daí, que tipo de som, que palavra pode vir daí? Essa é uma das bases do trabalho que estou desenvolvendo em minha residência no Movement Research.
\end{abstract}

Em uma retrospectiva recente do artista Mike Kelley, a gente encontrava uma crítica quase escatológica à competição nos EUA. Como se isso fosse um instinto esportivo que vai contaminando tudo o mais na cultura americana. Na performance e na dança contemporânea você diria que isso está presente também?

K.J. HOLMES - A competição em um nível de mercado é uma outra história. Mas, sim, há pessoas treinando por anos que querem usar sua técnica. $\mathrm{E}$ a natureza atlética disso está em um determinado prazer em se buscar os limites físicos.

\title{
E você se insere nesse contexto?
}

K.J. HOLMES - Eu venho enfrentando esse desafio de trabalhar a voz com uma especialista e sinto que esse é um dos lugares mais vulneráveis em nós. Ela consegue perceber e atentar para minhas limitações ou hábitos... Então, talvez haja algo como competir consigo mesmo.

Eu estou tentando lhe dizer também o seguinte: li uma crítica a esse 
último filme dos irmãos Coen, "Inside Lewyn Davis", em que se lamentava que a personagem principal - que aparece na cena musical, ao mesmo tempo em que ninguém menos que Bob Dylan - não tivesse talento para se estabelecer profissionalmente. Ou seja, nem a personagem pode falhar...

K.J. HOLMES - Nesse ponto de meu percurso, não se trata tanto de entender com quem estou competindo, mas como me estabeleço como uma artista em "meio de carreira", quando a cultura apoia muitos artistas emergentes. Essa é uma questão para mim, agora. Se você é um artista jovem, você está ali, no ápice do processo. Se você é um artista em meio de carreira, parece haver essa constatação: "Bom, isso é o que você faz", uma categorização. E, se você começa a explorar algo novo, você como que tem de se justificar: "Eu faço outras coisas, não só 'contato e improvisação"”.

\section{Como é sua relação com a teoria?}

K.J. HOLMES - Sempre fui uma leitora. Hoje acho que estou tentando ir mais fundo. Tenho estudado semântica, curiosa a respeito de Foucault. Eu venho usando um de seus livros, nem sempre como suporte teórico, mas as palavras mesmo como elementos para coreografia. A menção à Nave Louca, eu a utilizei recentemente em um trio em que explorei esse pretexto de que iríamos trabalhar bem próximos, coordenados, mas isso seria impossível.

Eu assisti e me pareceu que você estava praticamente "ensinando" os dois outros bailarinos como falhar.

K.J. HOLMES - Talvez. Há algo que me interessa quanto à questão de se falhar na dança, por conta de uma ênfase muito grande em um corpo fluido e eficiente. Eu me interesso pelo estranhamento. Tento fazer com que meus alunos valorizem aquilo que eles não sabem, para que não percam a chance de enfrentar e passar por certas dificuldades. E nessa sessão eu estava como que tentando levá-los a "não fazer", como se ao tentar fazer aquilo perfeitamente nós estivéssemos fadados a falhar.

Você mencionou esse aspecto pornográfico do espetáculo a que assistiu, por sinal, também em uma igreja. Enfim, eu me lembrei dessa noção de que o sexo explícito seria o fim de qualquer ilusão possível em 
relação ao corpo e queria saber se tem algo a dizer sobre a sexualidade no contexto da dança e da performance?

K.J. HOLMES - Particularmente esse espetáculo a que assisti está em um universo bastante diferente do meu. Ele estava voltado para o homem negro representado na arte, nas artes performáticas - não só homens negros, na verdade, mas também homossexuais e transgêneros. Eu conversei com o curador. Havia algo de pornográfico, sim, mas parecia quase vazio de qualquer tipo de impacto; o desafio de ir àquele extremo, quando ficamos anestesiados e nem mesmo enxergamos. Uma das coisas que experimentei no envolvimento com "contato e improvisação" é quase ter que evitar a sexualidade. $\mathrm{O}$ toque se torna um método para se criar movimento. E eu de fato tinha que me distanciar daquilo de modo a lembrar a intimidade do corpo de uma maneira diferente.

\section{Como se o "natural" não fosse o bastante.}

K.J. HOLMES - Ou pelo menos não para minha vida... E eu amo a forma. Mas tinha necessidade de retomar meu corpo como uma cidadã do mundo, no lugar de apenas uma dançarina ou uma performer. É sempre uma linha tênue quando seu corpo é o instrumento.

\section{Ser agente e objeto ao mesmo tempo?}

K.J. HOLMES - Sim. Por isso o público continua a ser importante. Não é só uma experiência voyeurística. Eu realmente acredito que a performance é uma forma de reformular isso. Se eu tenho uma verdade naquilo que estou fazendo, no sentido de acreditar naquele sistema que estou revelando, talvez o público possa realmente experienciar alguma coisa dessa situação. “Nós temos uma situação aqui!" Eu me transformo e esqueço que estou no palco, pois não é só para o artista, é pela troca, você estar na plateia e sentir o impacto.

Confesso que quando você falou isso no espetáculo, por não conseguir distinguir se era ou não um improviso, eu comecei a rir imaginando que, em outra situação cotidiana, alguém poderia lhe responder com algo como: "e quem se importa?!"

K.J. HOLMES - Sim, claro. Contextualmente ainda pode ter significados bem diferentes. 